\title{
Computational Model for Organizational Learning in Research And Development Centers (R\&D)
}

\author{
Marco Javier Suárez Barón ${ }^{[1]}$, José Fdo. López ${ }^{[2]}$, Carlos Enrique Montenegro-Marin ${ }^{[3]}$
} Paulo Alonso Gaona García ${ }^{[4]}$ and Franklin Guillermo Montenegro-Marin ${ }^{[5]}$

1 UPTC University, Faculty of Systems and Computing, Sogamoso, Colombia mailto:marco.suarez@uptc.edu.co

2 FUSM, Bogotá, Colombia - mailto:jflopezq@hotmail.com

3 Universidad Distrital Francisco José de Caldas, Bogotá, Colombia cemontenegrom@udistrital.edu.co

${ }^{4}$ Universidad Distrital Francisco José de Caldas, Bogotá, Colombia - pagaonag@udistrital.edu.co

${ }^{5}$ Universidad de Cundinamarca, Soacha, Colombia - fmontenegro@ucundinamarca.edu.co

\begin{abstract}
This work explains for a computational model design focused organizational learning in R\&D centers. We explained the first stage of this architecture that enables extracting, retrieval and integrating of lessons learned in the areas of innovation and technological development that have been registered by $R \& D$ researchers and personnel in social networks corporative focused to research. In addition, this article provides details about the design and construction of organizational memory as a computational learning mechanism within an organization. The end result of the process is discusses the management of the extraction and retrieval of information as a technological knowledge management mechanism with the goal of consolidating the Organizational Memory.
\end{abstract}

Keywords: Computational Architecture, Strategic Knowledge Management, Social Networks.

\section{Introduction}

Social networks are currently considered as the main tool for sharing information and data. In this research, information and data will be taken from lessons learned contained in specialized social networks focused on research and such as Research gate[1], LinkedIn[6] and Blogs[1]. Nevertheless, most of the research experiences and knowledge are not registered or used, and information is not being properly exploited in those networks.

As a solution for that, the use of computational models like Machine Learning or Deep Learning enables the structuring and integration of specialized knowledge acquired from significant experiences, such as lessons learned[7]. The application of these models allows for greater flexibility in the acquisition process and facilitates the capture, recovery, transfer, and reuse of knowledge. Implementing these technological platforms will provide the entire organizational structure with a crucial tool for decision-making and strategic planning on R \& D issues.

The paper is structured as follows: Section 2 describes the theoretical background, which involves Knowledge Management (KM) process and methods, models to manage knowledge on social systems and Learning technologies and organizational strategies to exchange knowledge; Section 3 details our proposed framework to combine and summarize research information and data to obtain final lessons learned; Section 4 presents results and discussion on the main components and phases of this computational model desing. Finally, in Section 5, we present our main conclusions and further works. 


\section{Background}

The generation of new knowledge is used for decision-making in non-simulated and simulated environments within the Learning process in the network. Planned R \& D entities are thus created to optimize processes, reduce costs, increase innovation, and consider new projects. Specifically, these entities will be the context in which individuals and the organization will learn more [2].

Despite scientific advances on this subject, there are still gaps in the analysis of information from social networks of investigative type whose content specifically covers issues related to science, technology and innovation. The social networks studied in this article and the information registered in these networks correspond specifically to academic, business and scientific social networks, although, for this work we used information contained in Twitter social network for the extracting and integrating process.

The application of Machine Learning enables the structuring and integration of specialized knowledge acquired from significant experiences, such as lessons learned [3]. The application of these models allows for greater flexibility in the acquisition process; it facilitates the capture, recovery, transfer, and reuse of knowledge.

Social media has increased interest in our daily activities, and the user profile of each individual is considered a significant source of information [3]. Both Web sites and social networks are potential tools for the management, updating, and exchange of information and knowledge in fields that are interested in knowing the knowledge. The basic, thoughts, ideas, relationships and activities of each individual in their environment, such as marketing.

On the basis of this concept, Knowledge Management (KM) theories center on mechanisms to help maintain knowledge within an organization. According to [4], as KM theory evolved, different models were proposed for innovation management in companies from multiple sectors in France and Germany, which have led us to focus our work primarily on the concept of Personal Knowledge Management (PKM), one of the most recent lines of work in this field [5].

\section{Methodology}

To further boost competitiveness in an R\&D center, the organization needs to learn from its current and past experiences in R\&D. Additionally, it is advisable to take advantage of their experiences, physical repositories in this domain of knowledge since a large volume of information and trends in $\mathrm{R}+\mathrm{D}+\mathrm{i}$ has been published in corporate social networks.

Additionally, the process of designing the proposed architecture revealed two methodological perspectives in the existing technologies to support knowledge administration systems, which correspond to two discrete dimensions of knowledge management, according to [18] and to [19]. These two perspectives were used as the methodology for producing this paper and are explained below.

Firstly, the proposed knowledge management system is based on the process-centered perspective, understanding knowledge management as primarily a social communication process that can be improved by considering aspects of support to collaborative group work [14].

In the computational architecture, the process-centered approach focuses on individuals, as the most significant source of knowledge within an organization, and upholds the idea of resolving the cooperation problems amongst them through a process to achieve their social commitment to transfer and share knowledge.

The second approach is known as the product centric perspective [19], which in this project is directed at the creation, storage, and reuse of knowledge documents in the organizational memory, grounded in computer sciences. This approach was at the core of this research project, primarily because it is based on the idea of explicitly stating, documenting, and formalizing knowledge for use as a tangible resource, and attempts to present correct sources of information to the final users at the appropriate time.

Organizational memory should provide mechanisms for storage and use of all formal and informal knowledge that exists within the organization [2]. Organizational memory derives from documents, good practice guides, manuals, and books that help improve the performance of the members of the organization.

Through this approach, we noted the importance that knowledge management has gained, even from a strictly economic perspective, which has led to the rise of numerous information technology-based tools. These tools provide mechanisms for shaping the individual knowledge of employees into the collective knowledge of the community [20]. Table 1 shows how the proposed architecture differs from other learning models, given the lack of consensus on the definition of many of the concepts and terms used in the organizational learning [21] and knowledge management fields. 
Table 1. Contributions to Scientific Knowledge in Research. Source: Authors

\begin{tabular}{|c|l|}
\hline Component & \multicolumn{1}{|c|}{ Functional features and original scientific contributions } \\
\hline Metamodel & $\begin{array}{l}\text { Integrates three levels of tasks (processing, knowledge, and } \\
\text { learning), while the current models do not integrate these three } \\
\text { functional levels. }\end{array}$ \\
\hline Ontology & Ontology structure. \\
\hline $\begin{array}{c}\text { Social } \\
\text { Analysis }\end{array}$ & $\begin{array}{l}\text { Facilitates the necessary changes and transformations in R\&D } \\
\text { centers }\end{array}$ \\
\hline $\begin{array}{c}\text { Extraction } \\
\text { retrieval } \\
\text { of } \\
\text { learnons }\end{array}$ & $\begin{array}{l}\text { Applied in syntactic/morphological analysis of the grammatical } \\
\text { structure in texts that contain lessons learned. }\end{array}$ \\
\hline $\begin{array}{c}\text { Semantic } \\
\text { analysis } \\
\text { lessons learned }\end{array}$ & $\begin{array}{l}\text { Assists in self-correlation and establishing relationships of } \\
\text { similarity and contrast between the strategies. }\end{array}$ \\
\hline $\begin{array}{c}\text { Organizati } \\
\text { onal Memory } \\
\text { (OM) }\end{array}$ & $\begin{array}{l}\text { Real time creation of the OM or ranges defined by the user based } \\
\text { on model of creation of semantically analyzed packets of } \\
\text { information. }\end{array}$ \\
\hline $\begin{array}{c}\text { Mearning } \\
\text { Machine }\end{array}$ & $\begin{array}{l}\text { Application of information analysis models and application of } \\
\text { algorithms and methods for text analysis }\end{array}$ \\
\hline
\end{tabular}

\section{Foundations and Discussion}

\subsection{Framework Design}

In the framework purposed, the process-centred approach focuses on individuals, as the most significant source of knowledge within an organization, and upholds the idea of resolving the cooperation problems amongst them through a process to achieve their social commitment to transfer and share knowledge. The basic methods used in this approach, such as Computer-Supported Cooperative Work, Workflow Administration, or processes training, among others, seek to foster communication and collaboration between individuals [24].

The framework used in this research project enabled the authors to standardize concepts, practices, and criteria to apply to the proposed metamodel and served as a reference for confronting and resolving new test cases of a similar nature.

This framework also includes the promotion of new forms of knowledge capture, based on sources of information, such as lessons learned, that circulate in social networks. The generation of new knowledge is used for decision-making in non-simulated and simulated environments within the Learning process in the network. Planned R \& D entities are thus created to optimize processes, reduce costs, increase innovation, and consider new projects.

Specifically, these entities will be the context in which individuals and the organization will learn more. The framework objectives described above summarized in the functional components presented in Figure 1. 


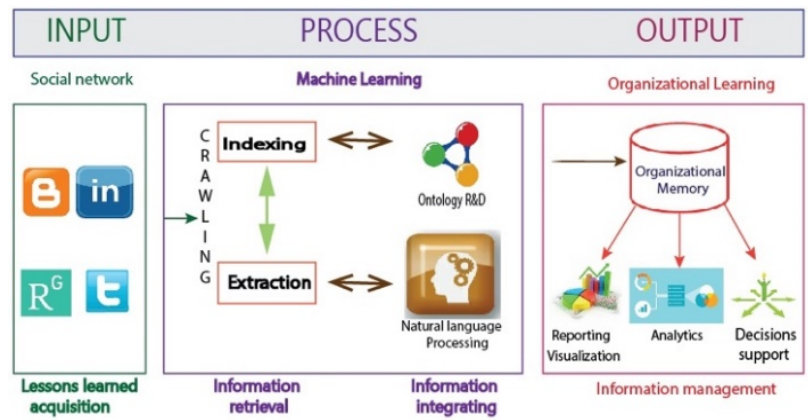

Figure. 1. Learning and organizational knowledge framework. Source: Authors

\section{Lessons learnt acquisition.}

In order to register information, we propose individual knowledge management (from tacit Knowledge to Explicit Knowledge). In this paper the information stored is called as lessons learned through social networks. Therefore, creating profiles for each individual or group of people is imperative for knowledge generation. On the basis of real time information retrieval (IR) algorithms, textual information is acquired and analyzed for lessons learned in the ranges or periods of time established by the users.

The acquisition of a lesson learnt, in the architecture represents the relationship between the result of a process, project, indicators, conditions or causes that align to the strategic plan of $\mathrm{R} \& \mathrm{D}$ for research center. The Figure. 2 shows and example of lessons learned registered in social network twitter.

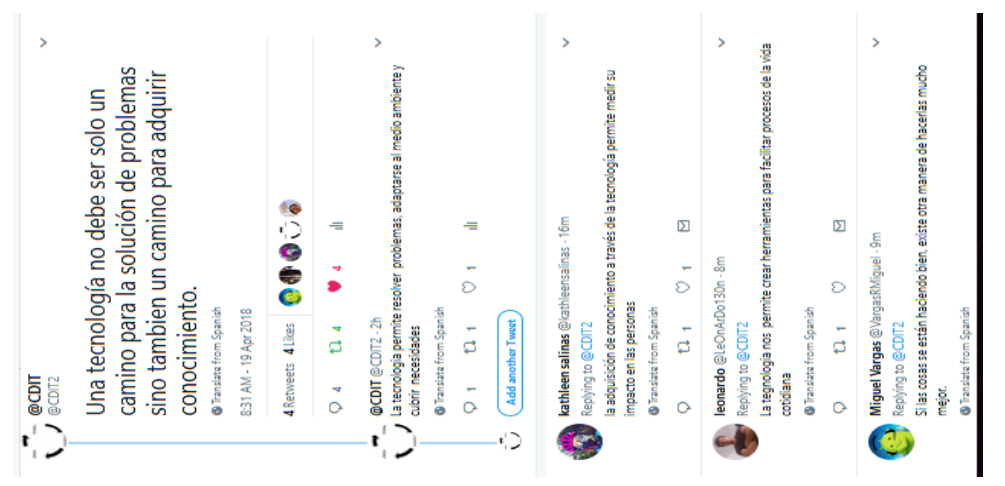

Figure. 2. Example of lessons learned registered in social network twitter.

To carry out the information extraction process, an application has been implemented for these three social networks; the application based on Python-social-auth technology allows the development in an agile way and provides the connection to numerous social networks with little configuration of parameters. The framework is integrated with certain profiles, this application allows access to tweets, retweets and mentions that refer to textual structures of topics related to R \& D lessons, the text structures are identified with a \# hashtag that will be defined by the research group or groups of researchers associated with the $\mathrm{R}+\mathrm{D}$ centers.

The mathematical model applied to obtain the associated trends (A, P, D) is showed in (1). The model analyze each lesson learned as an entity named defined "category" taken in ontology R\&D [20]. An example of this category can be resources, dates, places or processes.

$$
A_{v}=\sum_{n=1}^{\infty}(A, P, D) \quad \forall_{n}>\mathrm{C}
$$

Where:

$P \rightarrow$ Weight (I like it, comments): evaluate the number of Likes or retweets mad linked to each lesson registered. $D \rightarrow$ Registration time $=$ Determine the line time from lesson registered to first response; e.g. hours, days, minutes.

$\mathrm{n} \rightarrow$ Number of arcs $=$ Represent the thread or sequence for each lesson learnt.

Ac $\rightarrow$ Relevant publications $=$ Similarity R\&D terms for P, e.g. Synonyms, folksonomies, Hashtags. 
$\mathrm{A} \chi \rightarrow$ Identify the content relevance for extracting. If the relation is equal to zero, then the lesson learnt is not candidate for acquisition.

A scenario of analysis is give in the Table 1. In this case, the lesson "\#CDDI Una tecnología no debe ser solo un camino para la solución de problemas sino también un camino para adquirir conocimiento." is retrieved from twitter social network, see Figure. 2.

The relevance result is:

Table 2. Analysis of relevance for lessons learnt acquisition process.

\begin{tabular}{|c|c|c|c|c|c|c|}
\hline Lesson & Social Net & $\mathrm{P}$ & $\mathrm{D}$ & $\mathrm{Ac}$ & $\mathrm{n}$ & $\mathrm{A} \chi$ \\
\hline 1 & Twitter & 1 & 1 hour & 3 & 4 & 3 \\
\hline Thread 1.1 & Twitter & 1 & $3 \mathrm{~min}$ & 2 & 1 & 2 \\
\hline Thread 1.2 & Twitter & 0 & $11 \mathrm{~min}$ & 1 & 0 & 0 \\
\hline Thread 1.3 & $\begin{array}{c}\text { Twitter/Facebo } \\
\text { ok }\end{array}$ & 0 & 0 & 1 & 0 & 0 \\
\hline
\end{tabular}

The results can then be used to calculate aggregations, identify trends and produce reports, dashboards and performance measures.

\section{Retrieval and Integrating}

This component of the computational architecture makes it possible to determine the set of categories, groups, and trends related to the current status of knowledge acquisition and management on R\&D-related issues from lessons learned that have been structured through web service extraction. This process requires the application of linguistic techniques, using natural language processing [1].

However, the source data for this process is nominal data and unstructured text containing information on the concepts, profiles, categories, description, codes, events, and control, along with the terminology of the set of lessons learned in knowledge management for R\&D.

The information integration process involves a level of processing in which the application of ontology is crucial, given that the ontology enables the integration of specialized vocabulary into the knowledge domain. The tasks of indexing terms and linguistic concepts involved in ontologies make it possible to classify the topics, categories, entities (persons), and attributes of the entities mentioned in the lessons learned that are extracted.

Figure. 3 shows how the vocabulary "corpus" of data ontology allows the semantic indexing of scenarios such as: HR training, prototypes, patents, scientific articles, software registers. After the retrieval process all lessons learned are integrated and stored in a NoSQL structure.

For example, the word "management" can be changed in the word "administration"; To solve this lexical problem, this research adapts two approaches to the method of lexical variation ontological "lexical variation ontology". First, the method is applied in the English language corpus; in this case the variation must be made to a new corpus adaptable to the Spanish language since the language in which the lessons learned are recorded is Spanish. The main objective is to present a lexical ontology acquisition method that allows the variation of the noun and the verb through the generation of the corpus and the integration with the ontology of $\mathrm{R}+\mathrm{D}$ data.

The other hand, the grammatical decomposition aims to understand the semantic behavior of each word as an entity contained in the R \& D data ontology; Terms such as articles, connectors, links are discarded in the analysis process since they are not part of the set of terms included in the Ontology. 


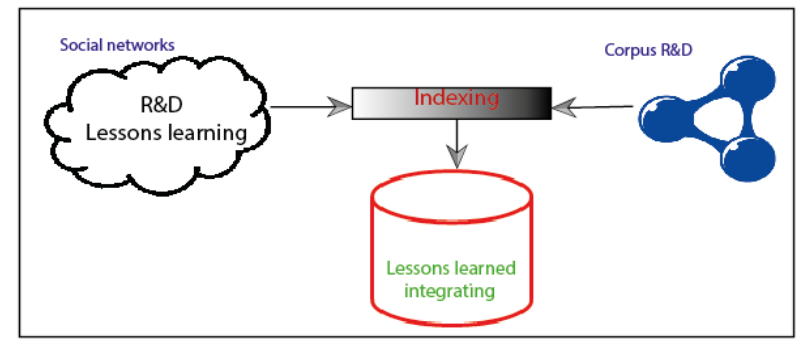

Figure. 3. R\&D organizational learning process.

The model requires machine learning techniques for social analysis is a mechanism that is thought-out to implementation in the second stage of this project., this is a We Development an experimental non-probabilistic prediction prototype focused unstructured information lexical analysis; lessons recorded in social networks for corporative environments, which can be used and extended to other types of organizational R\&D structures, either government or private.

\section{Information Management (I.M)}

This component involves the storage subsystem that offers the opportunity to integrate the necessary repositories and supports about the structural conformation of the lesson learned into the computational architecture. The information initially captured on corporative social networks allows real time collection of lessons learned and documents from each social network [2]. In the architecture, the I.M proposes the collection of information packages from Research gate, blogs, LinkedIn, and digital repositories; this workflow is supported by information integrating repository explained in Figure. 3.

The type of information to be considered for extracting and social analysis stems from the tacit and explicit knowledge of the R\&D staff. Within the organization, is relevant the organizational maturity regarding the use and application of corporate social networks as a collaborative tool for organizational knowledge transfer.

Figure. 4 displays the standardized interface in order to optimize the ability to search, retrieve and analyze the texts of lessons learned extracted. In this case, the capture and extraction of texts from the twitter social network is presented. Through the use of text and semantic analysis techniques, like Latent Semantic Indexing, LSI, [22], it is possible to learn about the trends and reality of the knowledge that is being generated by the work teams, using the dissemination of lessons learned from each member of these teams. The result involves entities and concepts that are analyzed lexically and syntactically. Meanwhile, the semantic (structural) analysis given to each learned lesson make it possible to identify entities (see section 4.2) that are or are not contained within the R $+\mathrm{D}$ vocabulary.

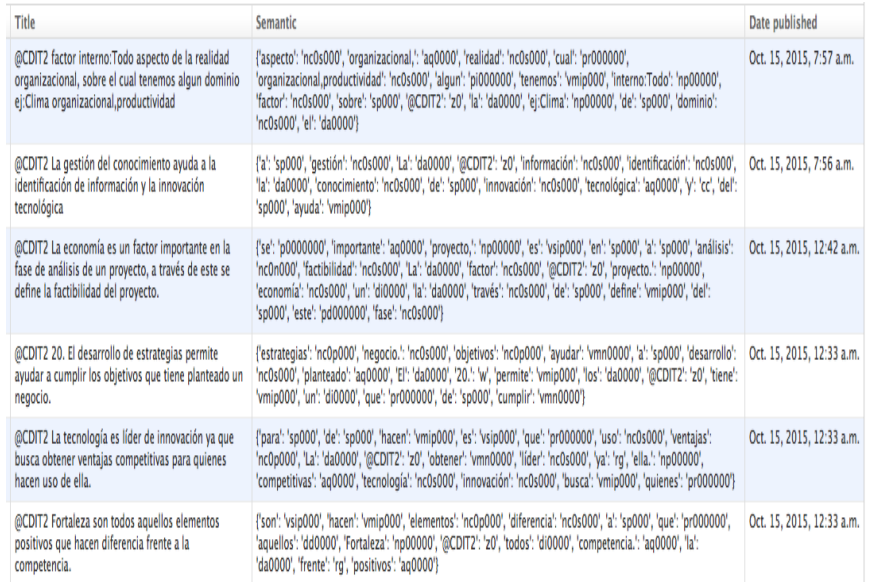

Figure. 4. Standardized interface of lessons learnt extracted using crawling 
After extracting and filtering the lessons learned from unstructured sources, such as blogs, tweets, and organizational forums, the next stage is to create an information management component for constructing and organizing the organizational memory $(\mathrm{OM})$. This is a continuous process and is at the core of the proposed platform. The lessons learnt filtering is supported by use of semantic indexing, in our approach the tool applied was ontology R\&D [1].

The tasks of filtering and integrating information or lessons learned are based on the R\&D ontology. The task of populating the organizational memory will be based on topics related to innovation and technological development for an R\&D center. The purpose of designing the $\mathrm{OM}$ is to structure informal, case-based information. The $\mathrm{OM}$ also facilitates the automatic capture, retrieval, transfer, and reuse of knowledge. In information management, $\mathrm{OM}$ is defined as a flexible structure that enables the consolidation [23], in one sole repository, of all lessons learned on issues relevant to the R\&D knowledge domain. Therefore, the design of the OM begins with the individual memory of each member of the R\&D center and concludes with the creation of the collective memory.

In view of the above, organizational learning allows us to understand the impact of the opinions and perceptions of the human resources of the R\&D center in relation to certain knowledge or experiences, for example, technological management. The R\&D center can carry out periodic, offline analyses, through reports prepared on the basis of an analysis of the data from the OM obtained and formalized in real time. The framework allows for the incorporation into this analysis of an immense amount of spontaneous and real time information from social networks, forums, and blogs, to assess their impact on the thematic trends and behaviors and, thus, rapidly reveal both critical events and competitive advantages.

The Information Management component receives all packages of content in specific intervals of time (for example, daily or weekly) and analyses them to identify what is being mentioned in the R\&D center in relation to the technological and social variables, e.g. sentiments and emotions of what is being said about topics like technological management. The correlational analysis is combined with mathematical models and algorithms that accompany the factorial analysis. These two inputs can be applied to obtain the trends associated with each lesson learned in terms of the entity mentioned, the defined category, and relevant and non-relevant topics at the R\&D center.

\subsection{The organizational Learning Process}

The organizational learning process in the proposed architecture involves all activities related to knowledge storage and retrieval, and provides support by creating document repositories, forums, among other tools, to provide access to knowledge that serves for decision-making purposes at any given moment; thus, running the organizational memory like a cycle of Knowledge Management processes. The way the organizational memory is structured can establish six (6) categories of organizational memory of section 3.

From the perspective of business modelling language, ontologies provide a precise description of the concepts of the R\&D domain and the relationships between these concepts. Therefore, in organizational learning processes, ontology offers a basic vocabulary that is useful for strategic knowledge management and establishes two levels of abstraction: for knowledge management and for the representation of knowledge.

The most important function of an ontology is the need to reach a consensus on the knowledge of the domain within an organization, so that the knowledge represented is not the subjective perspective of an individual but, rather, is shared and accepted by a community committed to the principle of organizational culture, facilitating communication and interoperability amongst the members of the R\&D Centre.

Finally, Figure. 5 shows an of example dashboard obtained of the information that we have obtained from the previous processes and that feed the "tableau tool" for the comparison of the trends of lessons learned regarding the strategic axes of the R $+\mathrm{D}$ centres in period time one month. The analysis shows that in September 2017 there was a greater opinion tendency on R \& D Management (45.76\%) as in the month of October 2017 (33.93\%) and the trend of publications with respect to $\mathrm{R}+\mathrm{D}$ projects is greater with $75.00 \%$. 


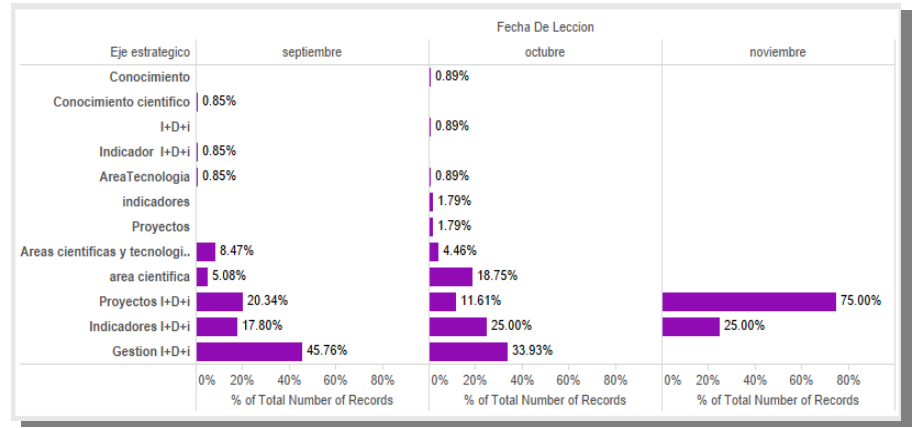

Figure. 5. Querying of the trends of lessons learned.

\section{Conclusions and Future Research}

In this paper is proposed the design of general architecture of a computational model driven to extraction, integrating and analysis not structured information obtained from scientific and academic social networks. The aim in this research is development an organizational learning system that apply new computational algorithms like natural language processing that allow organizational learning to be more effective and specific in R\&D centres.

The validation of the learning metamodel demonstrate that the components of the architecture in the innovation, research development domain, allows indexing and integrating information from the lessons learned through data ontologies. In the metamodel, the ontology was conceived as the conceptual scheme of data in relation to a specific subject but not as a mechanism of knowledge acquisition, in this case were terms semantically related to R \& D; this structure was also defined as a hierarchy of concepts that are characterized by properties and the relationship between all these entities. However, for the analysis of lessons from lessons learned with more complex lexical structures, the tokenization and standardization process is limited given that the set of labelling applied is still under testing for the Spanish language. From the point of view of the vocabulary used for indexing terms, the set of terms is limited to specialized concepts on technological surveillance, innovation, technological development and innovation. Finally, the ontology maintenance process is crucial in the growth of knowledge on the subject.

\section{References}

[1] Pico, B \& Suárez, M.: Organizational Memory Construction Supported In Semantically Tagged. International Journal of Applied Engineering Research, 41744-41748 (2015).

[2] Kirwan, C.: Making Sense of Organizational Learning: Putting Theory Into Practice. Farnham: Gower Publishing Limited (2013).

[3] Chiha, R., Ayed, M. B.: Towards an Approach Based on Ontology for Semantic-Temporal Modeling of Social Network Data. In International Conference on Intelligent Systems Design and Applications, pp. 708-717. Springer (2016).

[4] Fam, D.: Facilitating communities of practice as social learning systems: a case study of trialling sustainable sanitation at the University of Technology Sydney (UTS). Knowledge Management Research \& Practice, 391399 (2017).

[5] Haas, M.R; Hansen M.T.: Different knowledge, different benefits: Toward a Productivity perspective on knowledge sharing in organizations. Strategic Management Journal, vol. 28, pp. 1133-1153 (2010)

[6] Liana Razmerita, Kathrin Kirchner, Frantisek Sudzina, (2009) "Personal knowledge management: The role of Web 2.0 tools for managing knowledge at individual and organisational levels", Online Information Review, Vol. 33 Issue: 6, pp.1021-1039, https://doi.org/10.1108/14684520911010981 
[7] Tan, Wei ; Blake, M. Brian ; Saleh, Iman ; Dustdar, Schahram. / Social-network-sourced big data analytics. In: IEEE Internet Computing. 2013 ; Vol. 17, No. 5. pp. 62-69.

[8] Sinclaire, J. K., \& Vogus, C. E.: Adoption of social networking sites: an exploratory adaptive structuration perspective for global organizations. Information Technology and Management, vol. 12(4), 293-314 (2011).

[9] Chow, W. S., \& Chan, L. S.: Social network, social trust and shared goals in organizational knowledge sharing. Information \& management, 45(7), 458-465 (2008).

[10] Takeuchi, Riki; A Critical Review of Expatriate Adjustment Research Through a Multiple Stakeholder View: Progress, Emerging Trends, and Prospects ; Journal of Management ; Vol 36, Issue 4, pp. 1040 - 1064 ; First Published January 26, 2010; https://doi.org/10.1177/0149206309349308.

[11] Pirró, G.; Mastroianni, C.; Talia, D.: A framework for distributed knowledge management: Design and implementation. Future Generation Computer Systems. vol 26, 38-49 (2010). doi: 10.1016/j.future.2009.06.004

[12] Myong-Hun, C., \& Harrington, J.: Individual Learning and Social Learning: Endogenous Division of Cognitive Labor in a Population of Co-Evolving Problem-Solvers. Administrative Sciences, 53-75 (2013).

[13] Breslin, J.; Decker, S.: The future of social networks on the internet: the need for semantics. IEEE Internet Computing, vol. 11(6), 86-90, (2007). doi: 10.1109/MIC.2007.138.

[14] Fernández-Mesa, A., Ferreras-Méndez, J., Alegre, J., \& Chiva, R.: Shedding New Lights on Organisational Learning, Knowledge and Capabilities. Newcastle: Cambridge Scholars Publishing (2014).

[15] López-Quintero, J., Cueva Lovelle, J., González Crespo, R., \& García-Díaz, V.: A personal knowledge management metamodel based on semantic analysis and social information. Soft Computing, 1-10 (2016).

[16] Kamasat, R., Yozgat, U., \& Yavuz, M.: Knowledge process capabilities and innovation: testing the moderating effects of environmental dynamism and strategic flexibility. Knowledge Management Research \& Practice, 356-368 (2017).

[17] Espinoza Mejía, M., Saquicela, V., Palacio Baus, K., \& Albán, H.: Extracción de preferencias televisivas desde los perfiles de redes sociales. Politécnico, 34(2), 1-9 (2014).

[18] Peis, E., Herrera Viedma, E., Montero, Y. H., \& Herrera Torres, J. C.: Análisis de la web semántica: estado actual y requisitos futuros. El profesional de la información, 12(5), 368-376 (2003).

[19] Abecker, A.; Bernardi, A.; Hinkelmann, K.; Kuhn, O.: Toward a Technology for Organizational Memories. IEEE Intelligent, vol. 13(3), 40-48 (1998). doi: 0.1109/5254.683209.

[20] Suárez Barón,M.J. 2017. Applying Social Analysis for Construction of Organizational Memory of R\&D Centers from Lessons Learned. In Proceedings of the 9th International Conference on Information Management and Engineering (ICIME 2017). ACM, New York, NY, USA, 217-220. DOI: https://doi.org/10.1145/3149572.3149604

[21] Barão, A., de Vasconcelos, J., Rocha, Á., \& Pereira, R.: Research Note: A knowledge management approach to capture organizational learning networks. International Journal Of Information Management (2017). doi:10.1016/j.ijinfomgt.2017.07.013.

[22] Różewski, P., Jankowski, J., Bródka, P., \& Michalski, R.: Knowledge workers' collaborative learning behavior modeling in an organizational social network. Computers In Human Behavior, 1248-1260 (2015).

[23] Van Grinsven, M., \& Visser, M.: Empowerment, knowledge conversion and dimensions of organizational learning. The learning organization, 18(5), 378-391 (2011).

[24] Suárez Barón M.J., López J.F., Montenegro-Marin C.E., Gaona García P.A. (2018). Design of a Computational Model for Organizational Learning in Research and Development Centers (R\&D). In: Simari G., Fermé E., Gutiérrez Segura F., Rodríguez Melquiades J. (eds) Advances in Artificial Intelligence IBERAMIA 2018. IBERAMIA 2018. Lecture Notes in Computer Science, vol 11238. Springer, Cham 